\title{
Social Protection and the Labour Market: Towards a Research Agenda
}

\section{Francie Lund}

\begin{abstract}
1 Introduction
Social policies can be viewed as ways of addressing basic human rights; as ways of remediating and compensating for the inequalities associated with the capitalist organisation of production relationships; as a way of proactively redistributing wealth; and as an investment in human resources. Although there is some evidence of increasing acceptance of the idea of social protection being an investment in human resources, the mainstream of macroeconomics still largely sees labour as just another factor in production, or labour costs as a factor getting in the way of optimising economic growth.
\end{abstract}

In the WIEGO approach, we see social protection as an inalienable right of work. Informal employment is a permanent phenomenon (Chen et al. 2005 and this IDS Bulletin). As such, economic and social policies need to deal with it, rather than only present ways of how to escape from it. There is a stark mismatch between social policy and the realities of the labour market.

A number of conceptual frameworks have influenced recent policy thinking about social protections for informal workers. First, the Social Risk Management (SRM) approach (Holzmann and Jorgensen 1999) has had the advantage of allowing into the World Bank's neoliberal framework, the idea that some workers are vulnerable and that work itself can be a source of risk. Nevertheless, SRM has major conceptual problems. It takes the worker, the adult, as already a fully formed being, whose development was 'costless'. It then presents working people as being equally able to make rational choices to prevent or mitigate risks. It does not take into account the dynamics of exclusion from access to risk coverage, outlined in Martha Chen's contribution in this IDS Bulletin, which systematically and differentially disadvantage poorer people, and especially those in already vulnerable work situations.
Second, from the industrial development arena comes value chain analysis, which tries to understand how different industries can be made more competitive, through tracing the chain of activities involved in the design, production and marketing of products. Although there are variations in approach, they have in common with the SRM approach the key limitation that they take the worker at the point of production as 'ready-made'. There is little emphasis on the process of human development that it took to get her or him there, nor what it would take to assist him or her have a healthy and productive working life in the present, or in the future after retirement, or to transmit the possibility of improved life chances to children. An attempt was made to integrate an understanding of needs for and provision of social protection for informal workers into value chain analysis (Lund and Nicholson 2003), and this needs to be taken further.

Third, the International Labour Organization (ILO) has promoted the idea of 'Decent work for all' within the last decade, with 'for all' signifying its growing acceptance of informal employment. The associated campaign of 'extending social protection to all' also signals a more inclusive approach to 'work' and 'employment', an acceptance that there are workers who will not get access to work-related social protection through the implementation of ILO conventions on social protection. This ILO campaign on extension of social protection has, however, detracted attention from the process of informalisation that is underway, from the fact that on a daily basis, thousands of formal workers are losing access to existing measure of social protection.

Fourth, it is common to have support for small enterprises as part of programmes of poverty reduction, and indeed most international donors have this as a wing of their work. Commonly, 
however, there is a lack of understanding of the reality of the tiny size of the operation of most informal workers, and little emphasis on linking the formal and informal sectors. Insofar as the idea of small enterprise is so mistaken, being both genderblind and poverty-blind, then donor money is being used directly to bolster emerging elites, under the guise of poverty reduction interventions.

Fifth, a great deal of policy space in developing countries is currently being dedicated to promoting cash transfers as a form of poverty alleviation. Cash transfer programmes usually focus on women and children, and do not generally have any worker focus. Debates surround whether these should be universal or targeted, and whether they should be conditional (as in most of the Latin American programmes) or not (as in the child Support Grant in South Africa). The evidence for the benefits of cash transfers is widespread and convincing, but they are taking up a good deal of the available social policy space. The danger exists that, the better the evidence is that they are 'a good thing', the more that evidence can be used, opportunistically or not, to bolster the emerging idea emanating from the World Bank that the provision of core measures of social protection, such as health insurance and retirement provision, should be 'de-linked' from the labour contract. This approach has been advocated for the Latin American region specifically by the World Bank's Perry et al. (2007). Such 'de-linking' at a stroke removes direct employer responsibility for those who produce for them.

An outcome of the above combination of policy approaches is the witting or unwitting reinforcement of the invisibility of informal workers, as well as unrealistic estimations in social policy approaches and debates of poorer workers' ability to provide for themselves. It also detracts from the responsibilities of capital, and focuses on (unorganised) individuals, rather than organised workers; on the central state, rather than different levels of the state; and on citizens, rather than workers.

James Heintz in this IDS Bulletin argues that labour should be reconceptualised as a produced factor of production, and social protection as contributing to the macroeconomics of long-run economic growth. He holds that:

In short, social policies and social protections can contribute to macroeconomic performance, but it requires a change of mindset in which the production of human resources becomes integral to the functioning of the economy.

This opens the conceptual door to a longer-term view of the production, development and fulfilment of human beings, and this article seeks to contribute towards sketching elements of a research agenda that could hold the door open.

A conceptual theme that runs throughout is that of diversity and differentiation. The article by Martha Chen outlines various theoretical approaches to informal employment, and she points to the dangers that arise from simplistic, dichotomous analyses of formality vs. informality. She focuses on employment status as a key indicator for considering the risks faced by workers, and for social protection coverage of employment-related risks. This nuanced analysis is necessary if we are to pursue the conditions under which different kinds of workers - and especially poorer women - can get access to what core measures of provision.

\section{Pointers for a research and action agenda}

The following areas have emerged from WIEGO's social protection research and advocacy programme (Lund 2006). Some of them have become clear through WIEGO's interactions with both the World Bank and the ILO; others have presented themselves in WIEGO's work with member-based organisations of informally working women.

\subsection{Informalisation}

Half way through the twentieth century, the ILO committed itself to the goal of achieving universal coverage of labour standards and of social security. By the beginning of this century, it had scaled down its aspirations. It reduced its general comprehensive list of labour standards to four core labour standards, and retreated to an approach of 'minimum standards' of social security. The World Commission on the Social Dimensions of Globalisation for example asks for 'a minimum amount of social protection for individuals and families'.

In the 2004 'Peking Declaration', social security officials from more than 150 countries endorsed the idea of 'extending social security coverage', and in its 'Extending social protection' campaign, the central strategy and focus is to extend benefits to the previously excluded. This is laudable, and the 
approach does see social protection and good health as an investment, rather than as an economic cost. However, it has at the same time taken attention away from informalisation, the process by which workers who previously received social benefits lose access through being 'contracted out', 'casualised' or 'informalised'.

A substantial research commitment is needed that captures the global trends in the outcomes of informalisation for specific forms of social protection, and quantifies the numbers of workers involved by employment status and gender, and the types of benefits lost. This could be approached at first on a pilot country basis, preferably choosing countries in which there are consistently good labour force surveys or panel data, which capture work-related benefits. Such quantitative data could be supplemented with ethnographic studies of workrelated social benefits over time.

\subsection{Access to financial institutions and insurance}

Small-scale informal workers need resources to start their businesses, need to accumulate assets, and need to insure against a variety of risks. Microfinance, micro-savings and micro-insurance have been widely promoted as means of achieving these goals. Some schemes have been successful, reaching thousands, and being sustainable. Many have failed, as noted by Martha Chen in this IDS Bulletin.

Costa Rica provides an example of a government responding to the fact that an increasing portion of the workforce is informally employed, and not covered by the state's mandatory health and savings plans for formal workers. As described in a case study by Martinez-Franconi and Mesa-Lago (2003) and by Mesa-Lago in this IDS Bulletin, Costa Rica introduced a voluntary scheme for independent workers, and non-remunerated workers, such as unpaid family workers. It is a means-tested scheme aimed at those with no coverage, or limited former coverage, and is jointly contributed to by the state and the workers themselves. Uptake has been much higher for the health insurance component, than for the pensions component, possibly because there is already a noncontributory pension scheme for poor adult Costa Ricans.

SEWA's comprehensive social insurance scheme (Chatterjee and Ranson 2003) covers both selfemployed and wage workers, and has shown that it is possible for an organisation of poor workers to build a scheme from the bottom-up; that it is possible to go to scale as well as be flexible and worker managed; that women are more reliable savers and insurers than men are; and that claims for insurance can be contained. As Mirai Chatterjee (the head of SEWA's social security division) and Kent Ranson point out, it took SEWA a long time to expand to so many members, and it took especially long to convince the private insurance industry that poorer workers were insurable.

These are good examples. There is a gap, however, in knowledge about how the massive private insurance industry worldwide could be encouraged to extend its provision. Are there ways in which mainstream models of insurance could be used to extend to poorer workers, in a mix of private and public provision, where private experimentation and innovation is underwritten by the state? The following gives some avenues to explore.

First, formal insurance companies could be encouraged, possibly through a system of incentives from or underwriting by government, to develop products for and extend them to poorer working people. Relatively small tweaks for the industry, which make massive profits, could make a significant difference to the lives of millions of workers. The insurance industry is very good at providing policies to people for when they die, to cover funeral and associated costs. Could the insurance industry not also consider finding ways of assisting poorer workers to pursue their occupations when crisis hits? In South Africa, we find that many poor workers have two or even three life and funeral insurance policies, but nothing for the protection of income and assets - such insurance products are not available.

Second, there are high costs associated with establishing micro-insurance and savings schemes for limited numbers of people. Yet access to formal insurance and savings institutions is not affordable for poorer people. What are the possibilities for such schemes for poorer workers to be institutionally housed inside larger insurance institutions, with an element of subsidy from the larger to the poorer scheme, in the use of physical 'plant', information systems, communications systems and expertise?

Third, private homes are workplaces for millions of homeworkers, also known as industrial outworkers, 
the majority of whom are poor women who are in tenuous employment relationships with those for whom they produce. Take the example of a woman doing piecework stitching shoe uppers at home, with the completion of the shoe being done inside the formal factory. Her sewing machine is burned in a fire in her working room at home. What are the possibilities of extending the occupational insurance which covers the formal factory, to cover the premises of such an outsourced worker? It could be restricted only to work-related loss, not general household loss.

Fourth, many street vendors have no obvious employer. However, the municipality in effect controls many aspects of their working conditions, through its general approach to allowing street vending in public places, the provision (or not) of infrastructure, the issuing of permits to trade, for example. Is it possible for municipalities to extend their municipal staff insurance scheme, to allow access by informal workers? Informal workers could make a contribution; there need be no 'employer contribution', and the municipality could make a modest and affordable contribution from its budget, much as it already subsidises the private formal business sector in various visible and invisible ways. The regulating mechanism could be the licence to trade, which would provide an incentive for workers to formalise, with the rights and the responsibilities that that entails. Furthermore, could the municipality, which is a large client of a formal bank, encourage the bank to provide affordable savings accounts to informal workers?

These are some avenues whose feasibility could usefully be explored. Also, the social security division of the ILO is, with partner organisations dealing with formal insurance, exploring how to create linkages between informal workers and the insurance industry in the field of health insurance, and we need to learn from this initiative.

\subsection{Linking labour regulation, infrastructure and social provision}

The growth of informality has posed challenges to a number of disciplines, not least economics, and to a number of fields that have not conventionally been defined as being related to economic activities and work.

In the field of labour relations, labour regulation has traditionally been premised on work taking place in conventional places, such as shops, offices and factories, with clearly defined work relationships. There needs to be an integrative and comprehensive analytical framework, which incorporates new types of employment relationship, and different places of work.

The field of urban planning has traditionally separated out places where people live from places where people work - this distinction between residential and industrial is at the heart of land use zoning. Yet residential areas are increasingly being used for income-generating activities; public spaces such as parks and pavements are increasingly sites for vendors and service-providers; formerly formal commercial spaces in the heart of cities are being taken over by informal operators.

Research is needed that spells out the relationship between changing forms of work, and different needs for public sector provision of services (Terry McKinley notes in this IDS Bulletin that such public sector provision is an example of a structural policy intervention). More evidence is needed of the kinds of state support for services that can protect worker wellbeing, how the services interact with each other and precisely how they might contribute to higher incomes and more productive economic activity.

The following services are known to be important in their ability to enable people to work more productively, directly by reducing the fixed costs of meeting basic needs, and indirectly by assisting women in their work of maintaining households as social institutions:

- investments in health and education

- welfare services for women

- child care

- housing, as a place where people work as well as live

- infrastructural provision for people as citizens as well as workers - lighting, water, sanitation, rubbish removal, local roads.

A specific attempt should be made to include the role of sub-national and local governments in such analysis. In some countries, the local state may have as important a role to play as either the central state or more mainstream private sector support policies:

... it makes no sense at all to exclude [this] infrastructural support by local government from debates about how to reform the business 
environments of poorer working people ... we suggest that [the local state] has an indispensable role to play in effectively and affordably supporting the poor in their economic activities ...'

(Skinner and Lund 2005)

The Durban municipality, for example, introduced a range of innovative support measures to enable poor and marginalised street vendors to trade more productively, and in ways that were less in conflict with city management regulations. It was overwhelmingly clear that its freedom to innovate depended crucially on its not having privatised certain services and assets (Lund and Skinner 2005).

2.4 Specific social and economic measures for AIDS The HIV/AIDS epidemic is eroding social protection for working people, particularly across Africa. In research being done at the School of Development Studies at the University of KuaZulu-Natal, we see a number of factors converging to erode social security for poorer workers: formal insurance raises premiums, excluding more people from accessing private coverage; smaller informal insurance programmes, such as rotating credit associations, erode or implode through the sickness of members or of their families; more savings and other assets are drawn upon to be spent on health costs and on funerals; healthcare programmes cap the value of services, or the number of services offered.

AIDS has serious implications for what Caroline Moser has called 'community time'. Much of the work of building relationships and organisations and offering support at community level is done by women, yet women are now being called on to do 'community care' (Hunter 2005), with an assumption that their time is infinitely elastic. And they are withdrawing from productive work in order to do more unpaid care work (Akintola 2004; Chen et al. 2005). One has to be highly critical of the notion of 'community' when it is suggested as a source for the provision of social protection to poorer people. A gendered and class analysis will show the potential dangers posed by policies of 'community care' in entrenching inequality, and eroding the returns to women of participation in the community or the market. There is a need to understand better the shifting boundaries between state spending and provision, private sector spending and provision, and unpaid work (Chen et al. 2005); and between low paid care work on the market, and unpaid care work at home.
Labour market and social protection policies need to be scrutinised with an AIDS lens, to determine what specific interventions can be made to shore up individuals and households who are affected by the epidemic. Realistic policy responses are not easy to find, but those based on the realities of poorer people's working environments will have a better chance of making a difference.

\section{Conclusion}

Addressing the problem of work-related insecurity faced by the millions of informally working people, and especially the problems of poorer women workers, is both urgent and difficult. This article has purposely shied away from worthy, yet small projectbased interventions. There is a global crisis, and it will need large-scale institutional responses that cut across national boundaries.

A number of suggestions have been made. First, in addition to focusing on extending social protection to informal workers, there is a need to analyse and find policy responses which put a brake on the current loss of access to social protection faced by large numbers of workers every day. Second, in addition to promoting micro-savings and microinsurance, there is a need to investigate ways of getting the giant global insurance industry to extend insurance products to poorer workers, who it currently sees as 'an uninsurable risk', despite SEWA's proof to the contrary. The insurance industry derives immense profits from covering the risks of some, but on the whole, does little to contribute to the security of poorer working people. Third, finding appropriate solutions will require thinking outside of disciplinary boxes, integrating regulation of labour with regulation of physical space, and thinking beyond the national state as the main unit of analysis of governance, in particular so that the role of the local state can be included. Fourth, countries experiencing the severe AIDS epidemic need to integrate an understanding of the gendered effects of the epidemic on poorer women's access to the labour market, their care responsibilities, and the demands placed on them by policies of 'community care'. Policies that are both gender-blind and that see AIDS narrowly as a health issue are destined to be detrimental to women's economic position, and to the public good.

Realistic policies have to be based on concrete realities. It helps to incorporate heterogeneity rather 
than duality, and a continuum of work from most formal to most informal. The pyramid presented by Martha Chen is useful in this regard. It illustrates the segmentation that exists within the informal economy, and within the labour market as a whole, in earnings, in gender location and opportunities. Further work needs to be done which analyses socia

\section{References}

Akintola, Olagok (2004) A Gendered Analysis of the Burden of Care on Family and Volunteer Care-givers in Uganda and South Africa, Durban: Health Economics and HIV/AIDS Research Division, University of KuaZulu-Natal

Chatterjee, Mirai and Ranson, M. Kent (2003) 'Livelihood Security through Community-based Health Insurance in India', in Lincoln Chen, Jennifer Leaning and Vasant Narasimhan (eds), Global Health Challenges to Human Security, Cambridge: Global Equity Initiative, Asia Center, Harvard University

Chen, Martha, Vanek, Joann, Lund, Francie and Heintz, James, with Jhabvala, Renana and Bonner, Chris (2005) The Progress of the World's Women 2005: Women, Work and Poverty, New York: United Nations Development Fund for Women (UNIFEM)

Holzmann, R. and Jorgensen, S. (1999) 'Social Protection as Social Risk Management: Conceptual Underpinnings for the Social Protection Sector Strategy Paper', Journal of International Development 11.7: 1005-27

Hunter, Nina (2005) An Assessment of How Government's Care Policy is Working in Practice: Findings from KwaZulu-Natal, School of Development Studies Working Paper 42, Durban: University of Kua-Zulu Natal policy options in terms of their usefulness to different status of employment, in industrial sectors which employ many informal workers. This sort of differentiated analysis can enable the appropriate design of programmes, and incremental goal setting towards more comprehensive social security for informal workers.

Lund, Francie (2006) 'Working People and Access to Social Protection', in Shahra Razavi and Shireen Hassim (eds), Gender and Social Policy in a Global Context, Basingstoke: Palgrave Macmillan

Lund, Francie and Nicholson, Jillian (eds) (2003) Chains of Production, Ladders of Protection, Durban: School of Development Studies, University of Natal

Lund, Francie and Skinner, Caroline (2005) 'Local Government Innovations for the Informal Economy: Creating a Positive Investment Climate', Development Outreach 7.1: 21-3

Martinez-Franconi, Juliana and Mesa-Lago, Carmelo (2003) La Reforma de la Seguridad Social en Costa Rica en Pensiones y Salud: Avances, Problemas Pendientes y Recomendaciones, San Jose: Fundacio Frederich Ebert

Perry, Guillermo E., Maloney, William, Arias, Omar, Fajnzylber, Pablo, Mason, Andrew and SaavedraChanduvi, Jaine (2007) Informality: Exit and Exclusion, World Bank Latin American and Caribbean Studies, Washington DC: The World Bank

Skinner, Caroline and Lund, Francie (2005) 'Creating a Positive Business Climate for the Informal Economy: Reflections from South Africa', paper presented at the Donor Conference, Reforming the Business Environment, Cairo, November/December 